\title{
Overexpression of epithelial cell adhesion molecule as a predictor of poor outcome in patients with hepatocellular carcinoma
}

\author{
CHIH-JAN KO ${ }^{1,2}$, CHIA-JUNG LI ${ }^{3}$, MENG-YU WU ${ }^{4,5}$ and PEI-YI CHU ${ }^{6-8}$ \\ ${ }^{1}$ Department of General Surgery, Changhua Christian Hospital, Changhua 500; ${ }^{2}$ School of Medicine, \\ Kaohsiung Medical University, Kaohsiung 807; ${ }^{3}$ Research Assistant Center, Show Chwan Memorial Hospital, \\ Changhua 500; ${ }^{4}$ Department of Emergency Medicine, Taipei Tzu Chi Hospital, Buddhist Tzu Chi Medical Foundation, \\ New Taipei 231; ${ }^{5}$ Department of Emergency Medicine, School of Medicine, Tzu Chi University, Hualien 970; \\ ${ }^{6}$ School of Medicine, College of Medicine, Fu Jen Catholic University, New Taipei 242; \\ ${ }^{7}$ Department of Pathology, Show Chwan Memorial Hospital, Changhua 500; ${ }^{8}$ National Institute \\ of Cancer Research, National Health Research Institutes, Tainan 704, Taiwan, R.O.C.
}

Received April 2, 2018; Accepted July 13, 2018

DOI: $10.3892 /$ etm.2018.6794

\begin{abstract}
Cancer growth, metastasis and development are regulated by a number of genes, whose expression mediates important processes, including cellular plasticity, motility and internal interactions in the tumor microenvironment. The epithelial cell adhesion molecule (EpCAM) serves an important role in cell-cell migration and tumorigenicity, particularly metastasis. The aim of the present study was to measure EpCAM expression using immunohistochemistry and to investigate the association between clinicopathological features and prognosis in hepatocellular carcinoma (HCC). The results revealed that EpCAM expression may be a biomarker for poor prognosis in patients with HCC and may therefore be used to predict clinical outcome. The present study suggests that EpCAM expression in $\mathrm{HCC}$ can be considered as a routine biomarker for unfavorable prognosis and may provide a basis for the future development of anti-EpCAM-targeted therapy.
\end{abstract}

\section{Introduction}

In Taiwan, hepatocellular carcinoma (HCC) is the second-most common cause of cancer-associated mortality and its incidence is increasing (1). A number of risk factors for HCC have been

Correspondence to: Dr Meng-Yu Wu, Department of Emergency Medicine, Taipei Tzu Chi Hospital, Buddhist Tzu Chi Medical Foundation, 289 Jianguo Road, New Taipei 231, Taiwan, R.O.C.

E-mail: skyshangrila@gmail.com

Dr Pei-Yi Chu, Department of Pathology, Show Chwan Memorial Hospital, 542, Section 1, Chung-Shang Road, Changhua 500, Taiwan, R.O.C.

E-mail: chu.peiyi@msa.hinet.net

Key words: hepatocellular carcinoma, epithelial cell adhesion molecule, biomarker reported previously, including hepatitis B, hepatitis C, alcoholic liver disease and non-alcoholic fatty liver disease (2-4). In 2016, the reported outcome of HCC was poor, with a high mortality rate $(35.5 / 100,000)$ in Taiwan (5). Current targeted and systemic therapies for HCC face a number of challenges, including drug toxicity and resistance (6). As such, the development of effective prediction and surveillance tools are necessary to enable early diagnosis, the prediction of clinical outcomes and personalized adjuvant treatments (7). Recent studies on HCC have focused on the development of high-throughput microarrays for predicting HCC prognosis (8-10). Several genes and proteins have been reported to be associated with HCC prognosis, including forkhead box M1 (FOXM1) (10), cyclin-dependent kinase 1 (Cdk1) (9), TP53BP1 and CDKN1B (8).

Typically, tumor progression occurs in two stages: Growth and distant metastases. Circulating tumor cells spread from the primary sites into the peripheral blood supply and arrive at the metastasis site; this process involves many genes $(11,12)$. Recurrent, high-grade and distant metastases indicate invasive circulating tumor cells, which are responsible for poor prognosis in HCC patients (13). A transmembrane glycoprotein-epithelial cell adhesion molecule (EpCAM; CD326) serves an important role in the distant metastasis of HCC (14). Ber-EP4 is a monoclonal antibody that effectively labels EpCAM in epithelial tissues and has been widely used to differentiate mesothelioma, adenocarcinoma and basal and squamous cell carcinomas $(15,16)$. However, few studies have analyzed the association between EpCAM expression and HCC prognosis. The aim of the present study was to analyze tumor and normal tissue samples from Taiwanese patients with HCC who had not previously received chemotherapy or targeted therapy in order to determine whether EpCAM expression is an independent clinicopathological indicator of HCC.

\section{Patients and methods}

Patients. A prospective search was performed in Changhua Christian Hospital to identify patients with HCC diagnosed 
between July 2011 and November 2013 at the Division of General Surgery, Department of Surgery, Changhua Christian Hospital, Taiwan. The present study was approved by the Institutional Review Board of Changhua Christian Hospital (CCH IRB number: 120504). Informed consent was obtained from all included patients. The inclusion criteria were as follows: HCC diagnosis, no previous chemotherapy or targeted therapies. The exclusion criteria were as follows: Age $<18$ years, pregnancy, previous chemotherapy, targeted therapy, or surgical intervention. All included patients received curative surgical treatment and long-term follow-up. The demographic and clinical data, including pathological stage, operative procedure and surgical outcome, were recorded and patients were monitored until death, censorship, or loss to follow-up. The Child-Pugh score predicted the clinical outcome. Following surgical resection, primary tumor tissues and matched adjacent normal tissues were collected and analyzed using a tissue microarray. The follow-up duration was defined as the period between the date of surgical intervention to the date of last visit or death. Patients were categorized into the low expression and high expression groups depending on EpCAM expression. The median EpCAM expression in the tumor group was used as the cut off value.

Immunohistochemistry (IHC) and scoring. To detect EpCAM expression, tumor specimens were embedded in paraffin, cut into $4-\mu \mathrm{m}$-thick sections and mounted on poly-l-lysine-coated slides. Subsequently, $10 \mathrm{mM}$ Tris- $\mathrm{HCl}(\mathrm{pH}$ 7.4) and $150 \mathrm{mM}$ sodium chloride were used to deparaffinize and rinse slides. Tissue was fixed with $4 \%$ paraformaldehyde for $10 \mathrm{~min}$ at room temperature, permeabilized with $0.1 \%$ Triton $\mathrm{X}-100$ for $10 \mathrm{~min}$ at room temperature, blocked with $3 \%$ bovine serum albumin (Sigma-Aldrich; Merck KGaA, Darmstadt, Germany) for $30 \mathrm{~min}$ at room temperature and incubated with EpCAM (Ber-EP4) monoclonal antibodies (cat. no. 61-0132-2; 1:100; Genemed Biotechnologies, Inc., South San Francisco, CA, USA) in blocking buffer for $1 \mathrm{~h}$ at room temperature. The slides were washed thrice with PBS and antibodies were detected using the EnVision Detection Systems Peroxidase/DAB, Rabbit/Mouse kit (Dako; Agilent Technologies, Inc., Santa Clara, CA, USA) and observed under a light microscope (BX50; Olympus Corp., Tokyo, Japan) at a magnification of x20 and x40. EpCAM expression was visualized in negative controls (adjacent normal tissues) by performing the same IHC steps, excluding the addition of the monoclonal antibodies. IHC results were evaluated by a professional pathologist and the scoring system considered two aspects: Staining intensity and percentage of positive cells. The staining intensity was scored using 4 grades as described previously $(17,18)$ : 0 , no expression; 1 , weak expression; 2 , moderate expression; and 3, strong expression. The IHC score ranged from 0 to 300 and was calculated using the following formula: Staining intensity x percentage of positive labeled cells

Statistical analysis. The association between EpCAM expression and the clinical and pathological parameters was analyzed using Chi-square and paired-sample t-tests. SPSS 13.0 (SPSS, Inc., Chicago, IL, USA) was used for all statistical analyses. Survival curves were plotted using the Kaplan-Meier method and compared using log-rank test. Cox's proportional hazards regression model was used to analyze the association between
Table I. Clinicopathological characteristics of patients with hepatocellular carcinoma.

\begin{tabular}{lc}
\hline Characteristics & Patient data \\
\hline Age (years) & $62.8 \pm 10.8$ \\
Sex, $\mathrm{n}(\%)$ & \\
Female & $50(27.0)$ \\
Male & $135(73.0)$ \\
Recurrence rate, $\mathrm{n}(\%)$ & $20(10.8)$ \\
Survival days & $857 \pm 342.5$ \\
Child-Pugh score & $4.79 \pm 1.8$ \\
Differentiation, $\mathrm{n}(\%)$ & \\
Well & $12(6.5)$ \\
Moderate & $97(52.4)$ \\
Poor & $76(41.1)$ \\
Clinical stage, $\mathrm{n}(\%)$ & \\
Stage I & $143(76.4)$ \\
Stage II & $21(11.4)$ \\
Stage III & $21(11.4)$ \\
Tumor size $(\mathrm{mm})$ & $45.9 \pm 37.2$ \\
Hepatitis B, $\mathrm{n}(\%)$ & $101(54.6)$ \\
Hepatitis C, $\mathrm{n}(\%)$ & $62(33.5)$ \\
\hline
\end{tabular}

the variables and survival data. $\mathrm{P}<0.05$ was considered to indicate a statistically significant difference.

\section{Results}

Patient characteristics. Patient characteristics are listed in Table I. A total of 185 patients (aged 26-81 years; mean, $62.9 \pm 10.8$ years; male: Female, $73: 27)$ were included in the present study. The majority of patients had Child-Pugh score A (Child-Pugh points: $4.79 \pm 1.8$ ), with a mean tumor size of $45.9 \mathrm{~mm}$. The prevalence of hepatitis B and C was 54.6 and $33.5 \%$, respectively. Following surgical excision, pathology revealed moderately differentiated tumors in most patients $(n=97 ; 52.4 \%)$ and well-differentiated tumors in 12 patients (6.5\%), with poorly differentiated tumors in 76 patients $(41.1 \%)$. A total of 143 patients (76.4\%) were determined to have HCC at clinical stage I. The mean follow-up time was 857 days. During this period, $20(10.8 \%)$ patients experienced tumor recurrence.

EpCAM expression. IHC staining revealed that all $185 \mathrm{HCC}$ and normal adjacent tissues were positive for EpCAM expression. EpCAM expression was upregulated in tumor tissues compared with matched adjacent normal liver tissues (Fig. 1A). In addition, EpCAM expression was significantly higher in HCC tissues compared with the paired adjacent normal liver tissues $(\mathrm{P}<0.001$; Fig. 1B). The authors of the current study hypothesized that high EpCAM expression promotes poor clinical outcomes in the low-expression group. Among the clinicopathological parameters assessed, the differentiation grade was positively associated with high EpCAM expression $(\mathrm{P}<0.05$; Table II). No significant association was observed between high EpCAM expression and hepatitis B or C. 

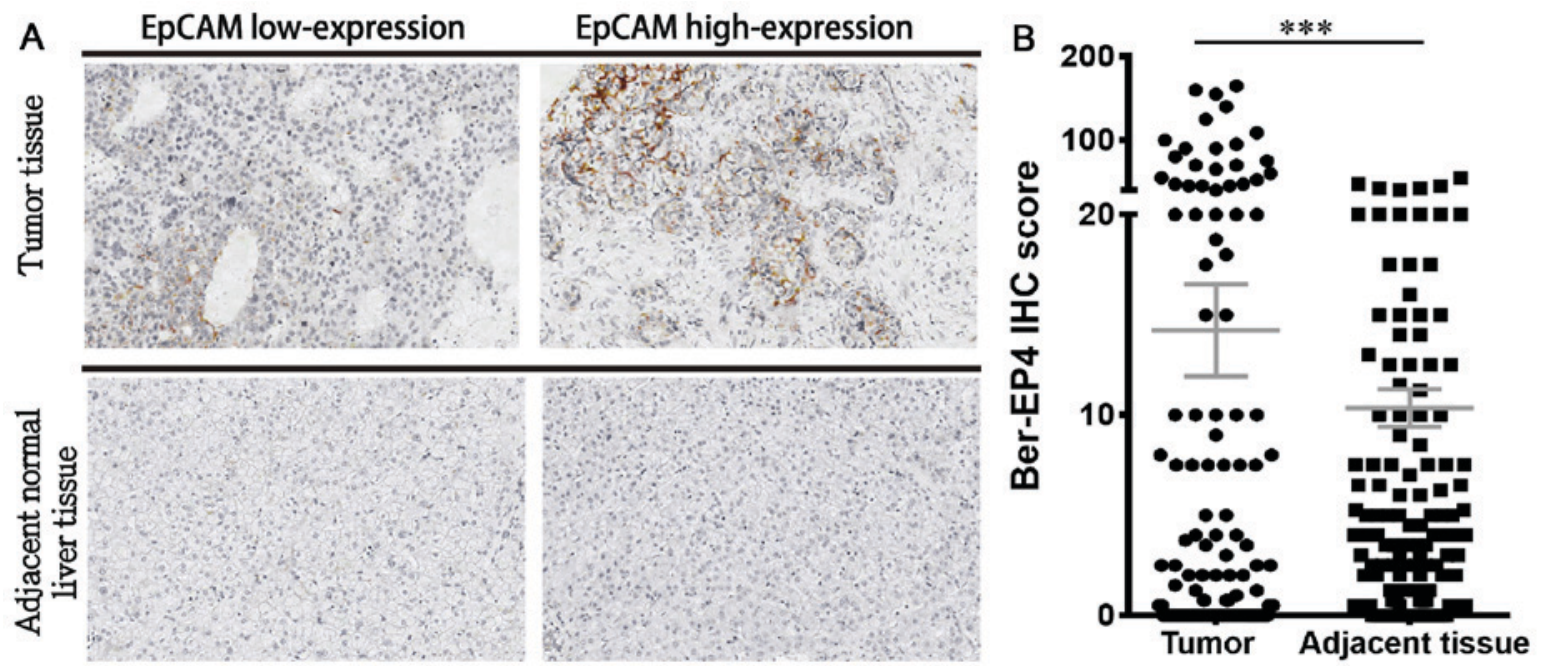

Figure 1. EpCAM expression in tumor and matched adjacent normal liver tissues from patients with hepatocellular carcinoma. (A) Representative IHC tissue samples from the EpCAM low-expression and high-expression groups. (B) Quantified EpCAM expression in tumor and adjacent normal liver tissues. Magnification, $\mathrm{x} 100 .{ }^{* * *} \mathrm{P}<0.001$. EpCAM, epithelial cell adhesion molecule; IHC, immunohistochemistry.

Table II. Association between clinicopathological characteristics and epithelial cell adhesion molecule expression in patients with hepatocellular carcinoma.

\begin{tabular}{|c|c|c|c|}
\hline \multirow[b]{2}{*}{ Variables } & \multicolumn{2}{|c|}{ EpCAM } & \multirow[b]{2}{*}{ P-value } \\
\hline & $\begin{array}{c}\text { Low } \\
\text { expression }\end{array}$ & $\begin{array}{c}\text { High } \\
\text { expression }\end{array}$ & \\
\hline Age (years) & $63.2 \pm 11.6$ & $62.1 \pm 9.6$ & 0.292 \\
\hline Sex, $n$ & & & 0.511 \\
\hline Female & 27 & 23 & \\
\hline Male & 65 & 70 & \\
\hline Recurrence, $\mathrm{n}$ & & & 0.354 \\
\hline Negative & 80 & 85 & \\
\hline Positive & 12 & 8 & \\
\hline Differentiation, $\mathrm{n}$ & & & 0.042 \\
\hline Well & 6 & 6 & \\
\hline Moderate & 40 & 57 & \\
\hline Poor & 46 & 30 & \\
\hline Clinical stage, $\mathrm{n}$ & & & 0.497 \\
\hline Stage I, II & 84 & 80 & \\
\hline Stage III, IV & 12 & 9 & \\
\hline Tumor size $\left(\mathrm{mm}^{2}\right)$ & $46.2 \pm 39.6$ & $45.6 \pm 34.9$ & 0.384 \\
\hline Hepatitis B, n & & & 1.000 \\
\hline Negative & 42 & 42 & \\
\hline Positive & 50 & 51 & \\
\hline Hepatitis C, n & & & 1.000 \\
\hline Negative & 61 & 62 & \\
\hline Positive & 31 & 31 & \\
\hline
\end{tabular}

Survival analysis. Overall survival analysis revealed a significant difference in two factors: Clinical stage and EpCAM expression $(\mathrm{P}<0.05$; Table III). The median survival time was
Table III. Univariate analysis of overall survival for patients with hepatocellular carcinoma.

\begin{tabular}{|c|c|c|c|}
\hline \multirow[b]{2}{*}{ Variables } & \multicolumn{2}{|c|}{ Overall survival } & \multirow[b]{2}{*}{ Log-rank } \\
\hline & $\begin{array}{l}\text { Median survival } \\
\text { days (n) }\end{array}$ & Survival (\%) & \\
\hline Sex & & & 0.904 \\
\hline Female & 895 & 86 & \\
\hline Male & 1,034 & 85.2 & \\
\hline Recurrence & & & 0.099 \\
\hline Negative & 935 & 83.6 & \\
\hline Positive & 634 & 100 & \\
\hline Differentiation & & & 0.175 \\
\hline Well & 860 & 100 & \\
\hline Moderate & 918 & 86.6 & \\
\hline Poor & 832 & 81.6 & \\
\hline Clinical stage & & & 0.003 \\
\hline Stage I, II & 928 & 87.8 & \\
\hline Stage III, IV & 642 & 66.7 & \\
\hline Hepatitis B & & & 0.967 \\
\hline Negative & 919 & 85.7 & \\
\hline Positive & 909 & 85.1 & \\
\hline Hepatitis C & & & 0.567 \\
\hline Negative & 915 & 84.6 & \\
\hline Positive & 895 & 87.1 & \\
\hline $\begin{array}{l}\text { Epithelial cell } \\
\text { adhesion molecule }\end{array}$ & & & 0.043 \\
\hline Low & 976 & 90.3 & \\
\hline High & 832 & 80.4 & \\
\hline
\end{tabular}

928 days for patients with stage I and II tumors and 642 days for patients with stage III or IV tumors. The median survival 
Table IV. Univariate and multivariate analyses of clinical characteristics in patients with hepatocellular carcinoma.

\begin{tabular}{|c|c|c|c|c|c|c|}
\hline \multirow[b]{2}{*}{ Variables } & \multicolumn{3}{|c|}{ Univariate analysis } & \multicolumn{3}{|c|}{ Multivariate analysis } \\
\hline & HR & $95 \% \mathrm{CI}$ & P-value & HR & $95 \% \mathrm{CI}$ & P-value \\
\hline \multicolumn{7}{|l|}{ Sex } \\
\hline Female & - & - & - & & & \\
\hline Male & 1.054 & $0.446-2.493$ & 0.904 & & & \\
\hline \multicolumn{7}{|l|}{ Recurrence } \\
\hline Negative & - & - & - & & & \\
\hline Positive & 0.043 & $0.000-13.801$ & 0.285 & & & \\
\hline \multicolumn{7}{|l|}{ Clinical stage } \\
\hline Stage I, II & - & - & - & - & - & - \\
\hline Stage III, IV & 3.487 & $1.465-8.302$ & 0.005 & 3.255 & $1.365-7.762$ & 0.008 \\
\hline \multicolumn{7}{|l|}{ Differentiation } \\
\hline Well or moderate & - & - & - & & & \\
\hline Poor & 1.734 & $0.815-3.690$ & 0.153 & & & \\
\hline \multicolumn{7}{|l|}{ EpCAM } \\
\hline Low & - & - & - & - & - & - \\
\hline High & 2.238 & $1.004-4.989$ & 0.049 & 2.108 & $0.943-4.712$ & 0.069 \\
\hline
\end{tabular}

HR, hazard ratio; CI, confidence interval; EpCAM, epithelial cell adhesion molecule.

time was 832 days in the group with high EpCAM expression (survival rate, 80\%) and 976 days in the group with low EpCAM expression (survival rate, 90\%).

The association between high EpCAM expression and clinical outcomes in HCC patients was investigated (Table II). Overall survival analysis revealed that patients with a high clinical stage and high EpCAM expression had lower survival rates and reduced survival duration, compared with those at clinical stages III and IV, and low EpCAM expression. Cox regression analysis confirmed the prognostic significance of a high clinical stage and high EpCAM expression (Table IV). Kaplan-Meier analysis revealed that patients with high EpCAM expression had a shorter overall survival time compared with those with low EpCAM expression (Fig. 2A); similar results were noted for high clinical stage and differentiation grade in patients with HCC (Fig. 2). These results suggest that high EpCAM expression serves an important role in determining the clinical outcomes of patients with $\mathrm{HCC}$.

\section{Discussion}

EpCAM is a transmembrane glycoprotein that regulates $\mathrm{Ca}^{2+}$-independent cell-cell adhesion via several functions, including cell migration, proliferation and differentiation (19-21). In addition, EpCAM is involved in c-Myc- and cyclin A/E-mediated cell cycle progression and proliferation (22). High EpCAM expression has been reported to be regulated by $\mathrm{Wnt} / \beta$-catenin signaling, which is responsible for the tumorigenic and invasive abilities of HCC (23). High EpCAM expression is reportedly associated with poor clinical outcomes in breast (24), ovarian (25) and esophageal squamous cell carcinoma (26). Furthermore, Schmelzer et al (27) has proposed EpCAM as a hepatic stemness marker. Together, these reports suggest that EpCAM may be a good marker for HCC prognosis.

In the present study, EpCAM expression in primary HCC was investigated, as well as its impact on clinical outcomes. The results revealed that high EpCAM expression was significantly associated with high differentiation grade. Bae et al (28) previously reported that high EpCAM expression was associated with high histologic grade, while EpCAM downregulation inhibited HCC proliferation. These findings support the results of the present study, which indicate that high EpCAM expression is associated with high differentiation grade and poor outcome. EpCAM immunoreactivity has been reported in 15.6-35\% of HCCs (29-31) and is associated with young age, poor differentiation grade and high clinical stage $(28,30,32,33)$. In the present study, EpCAM expression was significantly associated with differentiation grade; however, a high proportion of patients enrolled in the present study had stage I tumors (76.4\%) compared with previous studies $(28,34,35)$. Furthermore, no significant association was observed between EpCAM expression and clinical stage. However, Kaplan-Meier analysis demonstrated that EpCAM serves an important role in patients with tumors of high clinical stage. With regards to long-term patient follow-up, EpCAM expression was not significant in multivariate analysis.

The carrier rate of hepatitis $\mathrm{B}$ and $\mathrm{C}$ in Taiwan is high and these viruses induce rapid development of HCC (36). A number of oncogenes and DNA micromutations, including WNT, $\beta$-catenin, p53, Janus kinase, signal transducer and activator of transcription and mitogen-activated protein kinase-1, have been investigated in the progression and 

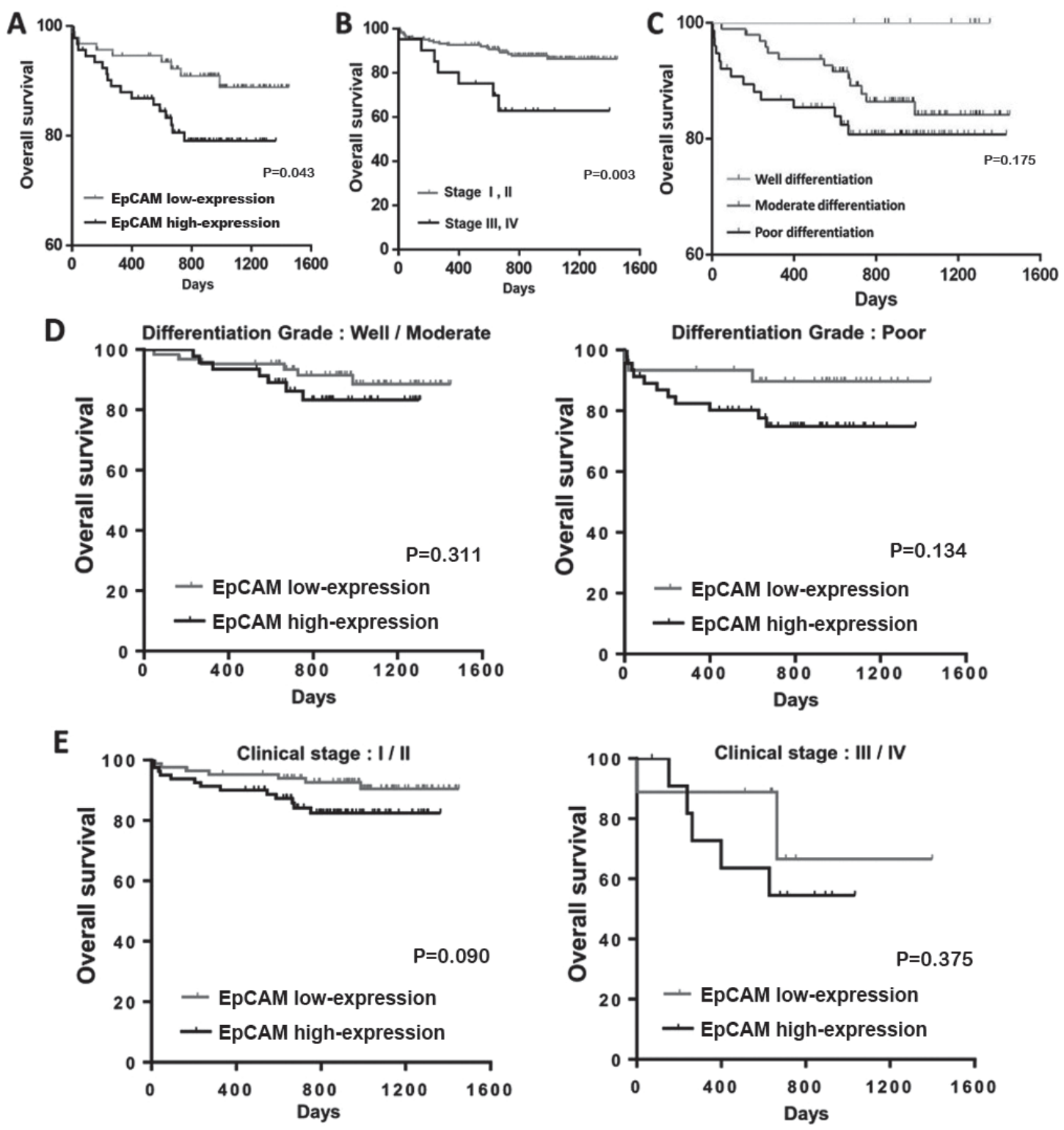

Figure 2. Kaplan-Meier analysis of the association between overall survival and (A) EpCAM expression, (B) clinical stage and (C) differentiation grade in patients with hepatocellular carcinoma. Kaplan-Meier analysis of the association between overall survival and (D) differentiation grade and (E) clinical stage in the EpCAM low-expression and high-expression groups. All comparisons were performed using the log-rank test. EpCAM, epithelial cell adhesion molecule.

development of hepatocarcinogenesis in patients with hepatitis B and C (37-39). However, few studies have investigated the novel biomarker EpCAM. Kimura et al (40) reported that high EpCAM expression is frequently observed in patients with hepatitis B virus. In addition, they demonstrated that EpCAM-expressing cells have high anti-cancer drug resistance. This trend was not observed in the present study. Furthermore, no significant difference was observed in overall survival analysis and Kaplan-Meier analysis. This may be due to a number of reasons; firstly, the patient sample was small and the effects of high-expression of EpCAM may not have been accurately detected. Secondly, a larger number of patients with stage I and II tumors were included in the present study compared with previous studies $(28,34,41)$. Previous studies have reported that EpCAM expression is more significantly associated with clinical outcome in high-stage tumors $(28,34,41)$. Thirdly, liver cirrhosis rates and Child-Pugh score were lower in in the present study compared with previous reports $(28,34,41)$. Although no association was observed between high EpCAM expression and poor clinical outcome in HCC patients with hepatitis B and $\mathrm{C}$ virus infection in the present study, we believe that such association may exist. Further studies are required to confirm the role of high EpCAM expression in HCC. The authors of the present study also believe that high EpCAM expression may be associated with poor prognosis in HCC. Thus, high EpCAM expression may be a prognostic factor of poor outcome in patients with HCC.

In conclusion, the present study suggests a potential role of EpCAM as an important risk factor for poor survival in HCC and EpCAM expression can be measured using routine IHC. Further studies are required to investigate EpCAM as a biomarker for HCC. The preliminary data herein suggests that HCC patients with high EpCAM expression may benefit from 
targeted therapy and immunotherapy. Thus, anti-EpCAM therapy is an appealing strategy for $\mathrm{HCC}$ and should be explored in the future.

\section{Acknowledgements}

Not applicable.

\section{Funding}

The present study was funded by the Ministry of Science and Technology, Taiwan (grant no. MOST 106-2314-B-442-001-MY3) and Show Chwan Memorial Hospital (grant no. RB17004).

\section{Availability of data and materials}

The datasets used and/or analyzed during the current study are available from the corresponding author on reasonable request.

\section{Authors' contributions}

CJK and CJL were involved in the acquisition and analysis of data. PYC and MYW were involved in the design of the study and organized the manuscript.

\section{Ethics approval and consent to participate}

The current study was approved by the Ethics Committee of Changhua Christian Hospital (Changhua, Taiwan, R.O.C.). All patients provided written informed consent.

\section{Patient consent for publication}

Not applicable.

\section{Competing interests}

The authors declare that they have no competing interests.

\section{References}

1. Chen DS: Hepatocellular carcinoma in taiwan. Hepatol Res 2 (Suppl 37): S101-S105, 2007.

2. Hung TH, Liang CM, Hsu CN, Tai WC, Tsai KL, Ku MK, Wang JW, Tseng KL, Yuan LT, Nguang SH, et al: Association between complicated liver cirrhosis and the risk of hepatocellular carcinoma in taiwan. PLoS one 12: e0181858, 2017.

3. Kim GA, Lee HC, Choe J, Kim MJ, Lee MJ, Chang HS, Bae IY, Kim HK, An J, Shim JH, et al: Association between non-alcoholic fatty liver disease and cancer incidence rate. J Hepatol 2: 32294-32298, 2017.

4. Huang YT, Yang HI, Liu J, Lee MH, Freeman JR and Chen CJ: Mediation analysis of hepatitis $\mathrm{b}$ and $\mathrm{c}$ in relation to hepatocellular carcinoma risk. Epidemiology 27: 14-20, 2016.

5. Altekruse SF, McGlynn KA and Reichman ME: Hepatocellular carcinoma incidence, mortality, and survival trends in the united states from 1975 to 2005. J Clin Oncol 27: 1485-1491, 2009.

6. Tazi el M, Essadi I, M'Rabti H, Touyar A and Errihani PH: Systemic treatment and targeted therapy in patients with advanced hepatocellular carcinoma. N Am J Med Sci 3: 167-175, 2011.

7. Yuan S, Wang J, Yang Y, Zhang J, Liu H, Xiao J, Xu Q, Huang X, Xiang B, Zhu S, et al: The prediction of clinical outcome in hepatocellular carcinoma based on a six-gene metastasis signature. Clini Cancer Res 23: 289-297, 2017.
8. Yu GP, Xiao QY, Shi ZQ, Tang LS, Ma XP, Zhang LY, Chen HT, Wang WJ, Zhang PY, Ding DL, et al: Genetic polymorphisms in apoptosis-related genes and the prognosis of hepatocellular carcinoma. Am J Cancer Res 5: 3249-3259, 2015.

9. Cai J, Li B, Zhu Y, Fang X, Zhu M, Wang M, Liu S, Jiang X, Zheng J, Zhang $X$ and Chen P: Prognostic biomarker identification through integrating the gene signatures of hepatocellular carcinoma properties. EbioMedicine 19: 18-30, 2017.

10. Song BN and Chu IS: A gene expression signature of FOXM1 predicts the prognosis of hepatocellular carcinoma. Exp Mol Med 50: e418, 2018.

11. Llovet JM and Bruix J: Testing molecular therapies in hepatocellular carcinoma: The need for randomized phase II trials. J Clin Oncol 27: 833-835, 2009.

12. Ringelhan M, Pfister D, O'Connor T, Pikarsky E and Heikenwalder M: The immunology of hepatocellular carcinoma. Nat Immunol 19: 222-232, 2018.

13. Zhou Y, Wang B, Wu J, Zhang C, Zhou Y, Yang X, Zhou J, Guo W and Fan J: Association of preoperative EpCAM circulating tumor cells and peripheral treg cell levels with early recurrence of hepatocellular carcinoma following radical hepatic resection. BMC Cancer 16: 506, 2016.

14. Wang MH, Sun R, Zhou XM, Zhang MY, Lu JB, Yang Y, Zeng LS, Yang XZ, Shi L, Xiao RW, et al: Epithelial cell adhesion molecule overexpression regulates epithelial-mesenchymal transition, stemness and metastasis of nasopharyngeal carcinoma cells via the PTEN/AKT/mTOR pathway. Cell Death Dis 9: 2, 2018.

15. Beer TW, Shepherd P and Theaker JM: Ber EP4 and epithelial membrane antigen aid distinction of basal cell, squamous cell and basosquamous carcinomas of the skin. Histopathology 37: 218-223, 2000.

16. Sheibani K, Shin SS, Kezirian J and Weiss LM: Ber-EP4 antibody as a discriminant in the differential diagnosis of malignant mesothelioma versus adenocarcinoma. Am J Surg Pathol 15: 779-784, 1991.

17. Chen YL, Chen PM, Lin PY, Hsiau YT and Chu PY: ABCG2 overexpression confers poor outcomes in hepatocellular carcinoma of elderly patients. Anticancer Res 36: 2983-2988, 2016.

18. Yu HC, Hung MH, Chen YL, Chu PY, Wang CY, Chao TT, Liu CY, Shiau CW and Chen KF: Erlotinib derivative inhibits hepatocellular carcinoma by targeting CIP2A to reactivate protein phosphatase 2A. Cell Death Dis 5: e1359, 2014.

19. Maetzel D, Denzel S, Mack B, Canis M, Went P, Benk M, Kieu C, Papior P, Baeuerle PA, Munz M and Gires O: Nuclear signalling by tumour-associated antigen EpCAM. Nat Cell Biol 11: 162-171, 2009.

20. Litvinov SV, van Driel W, van Rhijn CM, Bakker HA, van Krieken H, Fleuren GJ and Warnaar SO: Expression of Ep-CAM in cervical squamous epithelia correlates with an increased proliferation and the disappearance of markers for terminal differentiation. Am J Pathol 148: 865-875, 1996.

21. Osta WA, Chen Y, Mikhitarian K, Mitas M, Salem M, Hannun YA, Cole DJ and Gillanders WE: EpCAM is overexpressed in breast cancer and is a potential target for breast cancer gene therapy. Cancer Res 64: 5818-5824, 2004.

22. Chaves-Perez A, Mack B, Maetzel D, Kremling H, Eggert C, Harréus U and Gires O: EpCAM regulates cell cycle progression via control of cyclin D1 expression. Oncogene 32: 641-650, 2013.

23. Yamashita T, Budhu A, Forgues M and Wang XW: Activation of hepatic stem cell marker EpCAM by Wnt-beta-catenin signaling in hepatocellular carcinoma. Cancer Res 67: 10831-10839, 2007.

24. Spizzo G, Went P, Dirnhofer S, Obrist P, Simon R, Spichtin H, Maurer R, Metzger U, von Castelberg B, Bart R, et al: High Ep-CAM expression is associated with poor prognosis in node-positive breast cancer. Breast cancer Res Treat 86: 207-213, 2004.

25. Spizzo G, Went P, Dirnhofer S, Obrist P, Moch H, Baeuerle PA, Mueller-Holzner E, Marth C, Gastl G and Zeimet AG: Overexpression of epithelial cell adhesion molecule (Ep-CAM) is an independent prognostic marker for reduced survival of patients with epithelial ovarian cancer. Gynecol Oncol 103: 483-488, 2006.

26. Stoecklein NH, Siegmund A, Scheunemann P, Luebke AM, Erbersdobler A, Verde PE, Eisenberger CF, Peiper M, Rehders A, Esch JS, et al: Ep-CAM expression in squamous cell carcinoma of the esophagus: A potential therapeutic target and prognostic marker. BMC Cancer 6: 165, 2006.

27. Schmelzer E, Wauthier E and Reid LM: The phenotypes of pluripotent human hepatic progenitors. Stem Cells 24: 1852-1858, 2006 . 
28. Bae JS, Noh SJ, Jang KY, Park HS, Chung MJ, Park CK and Moon WS: Expression and role of epithelial cell adhesion molecule in dysplastic nodule and hepatocellular carcinoma. Int J Oncol 41: 2150-2158, 2012.

29. Yeh CT, Kuo CJ, Lai MW, Chen TC, Lin CY, Yeh TS and Lee WC: CD133-positive hepatocellular carcinoma in an area endemic for hepatitis B virus infection. BMC Cancer 9: 324, 2009.

30. Kim H, Choi GH, Na DC, Ahn EY, Kim GI, Lee JE, Cho JY, Yoo JE, Choi JS and Park YN: Human hepatocellular carcinomas with 'Stemness'-related marker expression: Keratin 19 expression and a poor prognosis. Hepatology 54: 1707-1717, 2011.

31. Yang XR, Xu Y, Yu B, Zhou J, Qiu SJ, Shi GM, Zhang BH, Wu WZ, Shi YH, Wu B, et al: High expression levels of putative hepatic stem/progenitor cell biomarkers related to tumour angiogenesis and poor prognosis of hepatocellular carcinoma. Gut 59: 953-962, 2010.

32. Shan YF, Huang YL, Xie YK, Tan YH, Chen BC, Zhou MT Shi HQ, Yu ZP, Song QT and Zhang QY: Angiogenesis and clinicopathologic characteristics in different hepatocellular carcinoma subtypes defined by EpCAM and $\alpha$-fetoprotein expression status. Med Oncol 28: 1012-1016, 2011.

33. Yamashita T, Forgues M, Wang W, Kim JW, Ye Q, Jia H, Budhu A, Zanetti KA, Chen Y, Qin LX, et al: EpCAM and alpha-fetoprotein expression defines novel prognostic subtypes of hepatocellular carcinoma. Cancer Res 68: 1451-1461, 2008.

34. Sung JJ, Noh SJ, Bae JS, Park HS, Jang KY, Chung MJ and Moon WS: Immunohistochemical expression and clinical significance of suggested stem cell markers in hepatocellular carcinoma. J Pathol Transl Med 50: 52-57, 2016.
35. Fong D, Seeber A, Terracciano L, Kasal A, Mazzoleni G, Lehne F, Gastl G and Spizzo G: Expression of EpCAM(MF) and EpCAM(MT) variants in human carcinomas. J Clin Pathol 67: 408-414, 2014

36. Liu CJ, Chen PJ, Chen DS, Tseng TC and Kao JH: Perspectives on dual hepatitis B and C infection in taiwan. J Formos Med Assoc 115: 298-305, 2016.

37. Hussain SP, Schwank J, Staib F, Wang XW and Harris CC: TP53 mutations and hepatocellular carcinoma: Insights into the etiology and pathogenesis of liver cancer. Oncogene 26: 2166-2176, 2007.

38. Vilchez V, Turcios L, Marti F and Gedaly R: Targeting Wnt/ $\beta$-catenin pathway in hepatocellular carcinoma treatment. World J Gastroenterol 22: 823-832, 2016.

39. Shi F, Lian S, Wu P and Shen L: Transarterial chemoembolization with or without microwave ablation in the treatment of intermediate (BCLC B) hepatocellular carcinoma. J Clin Oncol 35: e15635, 2017.

40. Kimura O, Kondo Y, Kogure T, Kakazu E, Ninomiya M, Iwata T, Morosawa $\mathrm{T}$ and Shimosegawa T: Expression of EpCAM increases in the Hepatitis B related and the treatment-resistant hepatocellular carcinoma. BioMed Res Int 2014: 172913, 2014.

41. Seino S, Tsuchiya A, Watanabe Y, Kawata Y, Kojima Y, Ikarashi S, Yanai H, Nakamura K, Kumaki D, Hirano M, et al: Clinical outcome of hepatocellular carcinoma can be predicted by the expression of hepatic progenitor cell markers and serum tumour markers. Oncotarget 9: 21844-21860, 2018. 